\title{
POR TODOS LOS MEDIOS. SUBVERSIÓN Y GOLPE DE FUERZA EN LA CONTRARREVOLUCIÓN. LAS EXPERIENCIAS DE GEORGES VALOIS (1906 - 1928)
}

\section{BY ANY MEANS. SUBVERSION AND COUP DE FORCE IN THE COUNTERREVOLUTION. GEORGES VALOIS' EXPERIENCES (1906 - 1928)}

\author{
Joan Pubill Brugués \\ Universitat Autònoma de Barcelona
}

\begin{abstract}
SUMARIO: I. INTRODUCCIÓN.- II. LA NOVEDAD ANTILIBERAL. EL ETHOS SUBVERSIVO DE LA CONTRARREVOLUCIÓN.- III. POR TODOS LOS MEDIOS. LA LEGITIMIDAD FRENTE A LO ILEGÍTIMO.- IV. LA NOVEDAD ANTILIBERAL. UNA TÁCTICA PARA UNA ESTRATEGIA MODERNA: LA NATURALEZA DE LA SUBVERSIÓN CONTRARREVOLUCIONARIA.- V. LA NACIÓN MOVILIZADA POR LA GUERRA. LA TOMA DEL PODER POR SUSTITUCIÓN (1916-1921).- VI. MATERIALIZAR LA SUSTITUCIÓN. LA CAMPAÑA CONTRA EL PARLAMENTO (1922-1924).- VII. UN VERANO CALIENTE. UNA MARCHA QUE PARECÍA IMPARABLE HACIA EL ESTADO NACIONAL (1926). VIII. CONCLUSIÓN: ¿POR TODOS LOS MEDIOS?
\end{abstract}

Resumen: El presente artículo pretende analizar la noción de golpe de fuerza que tenía contrarrevolución francesa en el primer tercio de siglo XX. A través de las numerosas tentativas subversivas de Georges Valois, uno de los modeladores de la cultura politica contrarrevolucionaria, se puede observar cómo las expresiones agresivas y las concepciones golpistas inherentes al ethos subversivo de la contrarrevolución no estaban reñidas con una táctica hacia el poder que contemplase procedimientos legales. Contrariamente a lo que se piensa, la praxis política de las principales fuerzas del momento, la Action Française, el Faisceau y las Jeunesses Patriotes, ponen de relieve que el asalto al poder podía ejecutarse "por todos los medios", no necesariamente los violentos.

\begin{abstract}
This article tries to examine the notion of coup de force of the French counterrevolution in the first third of the 20th Century. Through Georges Valois' numerous insurrectionary attempts, one of the masterminds behind the counterrevolutionary political culture, it can be examined how the aggressive expressions and insurgent conceptions inherent to the subversive ethos of the counterrevolution were not at odds with a tactic towards power that considered legal procedures. Contrary to what is generally believed, political praxis of the main contemporary formations, the Action Française, the Faisceau and the Jeunesses Patriotes, highlight that the seize of power could be executed "by any means", not necessary by violent ones.
\end{abstract}

Palabras clave: Georges Valois, Faisceau, Action Française, Jeunesses Patriotes, Subversión, Golpe de estado. 
Key Words: Georges Valois, Faisceau, Action Française, Jeunesses Patriotes, Subversion, Coup d'état.

\section{INTRODUCCIÓN}

Las experiencias de los años 30 han llevado a asociar comúnmente golpe de estado, subversión ilegal, insurrección violenta, todas ellas expresiones de un mismo campo semántico, a la praxis politica de la extrema-derecha hacia el asalto al poder. La vinculación parece lógica: son numerosos los estudios que se han centrado en el empleo de la violencia paramilitar por parte de la contrarrevolución como arma politica ${ }^{1}$. La Action Française (AF), las Jeunesses Patriotes (JP) y el Faisceau, las principales organizaciones contrarrevolucionarios que aquí se abordan, no fueron menos en el uso desmedido de la coacción y del atropello. Un periodista coetáneo puso de manifiesto que "si la porra es la arma de los camelots del rey, la vara la de los fascistas del Faisceau, el revólver es la de las Jeunesses patriotes" 2 . Sin embargo, la noción de subversión en la contrarrevolución va mucho más allá de la violencia, hasta el punto de que la relación entre toma de poder y praxis violenta es menos lineal de lo que se puede deducir de una cultura politica que tenía la subversión como su ethos.

Con el objetivo de reflexionar debidamente sobre este aspecto, se impone retroceder a principios de siglo XX, en el momento de eclosión de la cultura politica contrarrevolucionaria. La figura de Georges Valois sirve de hilo conductor para examinar el nudo histórico que aquí se plantea. Haciendo honor a lo que escribió en el primer número de sus Cahiers du Cercle Proudhon, cuando afirmó que "no separamos el pensamiento de la acción"3, sus diversos proyectos para asaltar el poder en 1916, 1920, 1923 y 1926 ejemplifican magníficamente el ethos subversivo de la contrarrevolución. Sus diversas experiencias en el campo de la contrarrevolución, primero como nacionalista integral y, a partir de 1925, como fascista en pugna con otras formaciones contrarrevolucionarias, proveen de un magnífico material para comprender la concepción insurreccional de una cultura política que él mismo contribuyó a modelar.

${ }^{1}$ La bibliografia es muy extensa. Para una visión general: Dirk Schumann, Political Violence in the Weimar Republic, 1918-1933: Fight for the Streets and Fear of Civil War, Berghan Books, Nueva York, 2012 [2001]; Robert Gerwarth y John Horne (eds.), War in Peace: Paramilitary Violence in Europe after the Great War, Oxford University Press, Oxford, 2012; Javier Rodrigo (ed.), Politicas de la violencia. Europa, siglo XX, Prensas de la Universidad de Zaragoza, Zaragoza, 2014. Para el caso francés: Sean Kennedy, "Pitfalls of Paramilitarism: The Croix de Feu, the Parti Social Français and the French State, 1934-1939", Journal of Conflict Studies, vol. 27, 2007, 64-79; Chris Millington, "Street-fighting Men: Political Violence in Inter-war France", The English Historical Review, vol. $129, \mathrm{n}^{\circ} 538,2014,606-638$.

2 C. F., "Nos enquêtes. Le fascisme en France. L'organisation armée des Jeunesses Patriotes", L'Ère nouvelle, 28 de diciembre de 1925, p. 2. Para una visión particular sobre el empleo de la violencia por parte de cada formación, ver: Rosemonde Sanson "Les jeunesses d'Action française avant la Grande Guerre”, en Michel Leymarie y Jacques Prévotat, L'Action française. Culture, société, politique, Presses du Septentrion, Villeneuve d'Ascq, 2008, 205-215; Allen Douglas, "Violence and Fascism: The Case of the Faisceau", Journal of Contemporary History, $\mathrm{n}^{\circ}{ }^{19}$, 1984, 689- 712; Robert Soucy, "Centrist fascism: The Jeunesses Patriotes", Journal of Contemporary History, vol. 16, $\mathrm{n}^{\mathrm{o}} 2$, 1981, 349-368.

3 Georges Valois, "Pourquoi nous rattachons à l'esprit proudhonien", Cahiers du Cercle Poudhon, ${ }^{\circ} 1$, enero-febrero de 1912, 34-47, p. 36. 


\section{LA NOVEDAD ANTILIBERAL. EL ETHOS SUBVERSIVO DE LA CONTRARREVOLUCIÓN}

La violencia o, para ser más precisos, el golpe de fuerza, es un leitmotiv inherente e inseparable a la contrarrevolución. Es evidente que la insurrección no constituía en sí una novedad en el imaginario colectivo del antiliberalismo. Las conspiraciones y las insurrecciones habian existido en determinados círculos boulangistas en 1889, quienes pretendian eliminar el régimen parlamentario ${ }^{4}$, en sectores del nacionalismo antisemita más visceral, como se demostró en el accidente del "Fuerte Chabrol" en $1898^{5}$, o en sectores radicales del carlismo español ${ }^{6}$. La novedad residia en que la contrarrevolución reflexionó por primera vez sobre la vía insurreccional como modus operandi. En 1910, salió editado Si le coup de forcé est possible. La obra estaba compuesta por una serie de artículos que Charles Maurras y Henri Dutrait-Crozon, nombre de pluma que ocultaba las identidades de los coroneles ligueurs Frédéric Delebecque y Georges Larpent, habian publicado en la revista L'Action Française durante los meses de enero, febrero y marzo de 1908, así como por fragmentos de L'Avenir de l'Intelligence (1905) y "Centralisation et conspiration", comunicación hecha por el provenzal en el congreso de diciembre de la liga realista en 1907, a modo de apéndices. La relevancia del texto se encuentra, precisamente, en el hecho de que se teorizaba "a cielo abierto" sobre la legitimidad del golpe desde una perspectiva moderna?.

La reflexión sobre el golpismo por parte del nacionalismo integral se contextualiza en el momento de eclosión de la liga como punta de lanza de ese nuevo espacio antiliberal que fue la contrarrevolución. Sus miembros estaban lejos de las veleidades patrióticas de los republicanos nacionalistas. En 1907, Henri Vaugeois, en calidad de presidente, fue tajante en la ambición de la organización: "Por todo el territorio, queremos crear un movimiento de opinión que sea tan intenso para suscitar, el día venidero, los hombres del golpe de mano" . Consideraban "duchas frías" las opciones electoralistas que defendia el otrora subversivo Paul Déroulède, dirigente de la Ligue des Patriotes ${ }^{9}$ " ¡El elector no se conmueve con la idea de poner un boletín de voto de más!", gritaba Maurras para criticar las ideas plebiscitarias ${ }^{10}$. Tampoco se mostraban

4 Jean Garrigues, "Le Général Boulanger et le fantasme du coup d'État", Parlement[s], Revue d'histoire politique, $\mathrm{n}^{\circ} 12,2009$, 43-48.

5 Se hablaría de "un golpe de estado fracasado». Jean-Paul Clébert, Fort Chabrol, Denoël, Paris, 1981, p. 9.

6 Por ejemplo, es el caso de "La Octubrada" de 1900, un intento de insurrección en el contexto de crisis postcolonial a espaldas del pretendiente Carlos, partidario de una conspiración más sibilina. Ver: Jordi Canal y Eduardo González Calleja, "NNo era la ocasión propicia...". La conspiración carlista de fin de siglo en un memorial a Don Carlos", Hispania, $\mathrm{n}^{\circ}$ 181, 1992, 705742 .

7 Charles Maurras y Henri Dutrait-Crozon, Si le coup de force est possible, Nouvelle Librairie Nationale, Paris, 1910, p. 7.

8 "Notre congrès. Première séance. Présidence d'Henri Vaugeois", L'Action Française bimensuelle, $\mathrm{n}^{\circ}$ 205, 1 de enero 1908, 6-10, p. 9.

9 Pierre Gilbert, "Une conférence de Paul Déroulède en 1909", L'Action française, 12 de junio de 1909, 1-2, p. 2. Para la figura subversiva de Déroulède entre 1898 y 1899, ver: Bertrand Joly, Déroulède, l'inventeur du nationalisme français, Perrin, París, 1998.

10 Charles Maurras, “Dictateur et Roi”, L’Action Française, 7 de abril de 1908, p. 1. 
indulgentes con la Patrie Française. Vaugeois escarnecería a los hombres de François Coppée y sus "pobres poemas en prosa que les sirven de programas" 11. La actitud beligerante se hacía patente cuando proclamaban que "no hace falta una revolución, hacen falta dos: una contra la República y la otra contra la Democracia" porque "asumimos conscientemente, en este doble juego, la profesión clara de revolucionarios" ${ }^{2}$. Para ello, se acompañó la retórica con una voluntad organizativa. El 8 de diciembre de 1905 se crearon los Étudiants d'Action Française $^{13}$. El 26 de noviembre de 1908, los Camelots du roi, cuya función era actuar como "policías suplementarios" y como "centro de propaganda" 14.

Fue en esa coyuntura que Alfred-Georges Gressent, anarquista dreyfusard profundamente desilusionando por la causa a favor del capitán ultrajado, vio en la liga realista una organización pujante capaz de dar un vuelco a la lastimosa situación que se había abierto en 1898. Su ingreso en 1906, cuando adoptó el seudónimo de Georges Valois, fue decisivo a la hora de conformar el ethos de la cultura política contrarrevolucionaria ${ }^{15}$. El recién llegado introdujo nociones del sindicalismo revolucionario a la doctrina del nacionalismo integral. El eje vertebral fue la concepción soreliana de la violencia ${ }^{16}$. A la convicción maurrassiana, donde la violencia era proactiva, un recurso que "ataca con el fin de prevenir el ataque opuesto"17, añadió los principios de la violencia tal y como Georges Sorel los habia teorizado para hablar de los mitos revolucionarios ${ }^{18}$. Esa fusión de conceptualizaciones no era artificial. Agrupaba bajo una misma matriz antiliberal las dos grandes tradiciones subversivas del momento, la realista y la sindicalista. Édouard Berth subrayó la coherencia. Mientras "se discute sobre si un golpe de fuerza es posible", subrayaba el discipulo de Sorel, "los sindicalistas rechazan dejarse engañar por las elecciones y preconizan la acción directa". E1 punto de unión era un menosprecio común hacia la modernidad: "Contra el oro, sólo hay el hierro que se le pueda imponer". Es decir, sólo quedaba el recurso "de la fuerza brutal"19.

11 Henri Vaugeois, “Coppée”, L’Action Française, 25 de mayo de 1908, p. 1.

12 Charles Maurras, "Balzac royaliste. Révolutionnaires comme Balzac", La Gazette de France, 19 de agosto de 1900 , p. 1.

13 Guillaume Gros, "Les Jeunes et l'Action française (1914-1939)", en Leymarie, Michel y Prévotat, Jacques (dirs.), L’Action Française... op. cit., 217-228.

14 Pierre Pujo, "Préface", de Steinbach, Guy, Histoire des Camelots du Roi, Les Documents d'Action Française, Presses Brettones, Saint-Brieuc, 1989, 1-2, p. 1.

15 Joan Pubill Brugués, Mort a la modernitat. La trajectòria inconformista de Georges Valois: de la crisi finisecular al feixisme, Universitat Autònoma de Barcelona, 2020.

16 Para Sorel, la violencia "», cuyo cimiento era la fuerza coercitiva. Georges Sorel, "Apologie de la violence. Hors la grève, pas de socialisme", Le Matin, 18 de mayo de 1908, p. 1. Para una interpretación de la violencia soreliana, ver: Claude Polin, "La violence de Sisyphe ou Georges Sorel et sa logique", en Sorel, Georges, Réflexions sur la violence, Rivière, Paris, 1972 [1908], VIIXLIV.

17 Charles Maurras, "La violence", L’Action française, 9 de enero de 1909, p. 1.

18 Georges Valois, "Sorel et l'architecture sociale", Cahiers du Cercle Proudhon, n 3-4, mayoagosto de 1912, 111-115, pp. 113.

19 Jean Darville [Édouard Berth], "Satellites de la Ploutocratie", Cahiers du Cercle Proudhon, $\mathrm{n}^{\circ}$ 5-6, septiembre-diciembre de 1912 (1913), 177-213, p. 207. 


\section{POR TODOS LOS MEDIOS. LA LEGITIMIDAD FRENTE A LO ILEGÍTIMO}

El ethos golpista de la contrarrevolución queda muy bien ejemplificado en la divisa "por todos los medios". Este lema, popularizado por la liga realista a principios de siglo, ponía de manifiesto la posibilidad de subvertir el orden a través de procedimientos ilegales. En D'un siècle à l'autre (1921), el primero de sus dos libros de memorias, Georges Valois confirmó que para "el derrocamiento de la República y la restauración o, más bien, ya que la monarquía nos parece rejuvenecida o, cuando menos, joven, la instauración de la monarquía" se contemplaban "todos los medios, incluso legales"20. Siguiendo la estela de los nacionalistas integrales, todas las formaciones cívico-politicas del espacio contrarrevolucionario compartirian esta mentalidad. Ya como dirigente del Faisceau, Valois mantendría esta misma concepción holística: "el objetivo es la destrucción del Estado parlamentario. Este es el resultado que debe obtenerse por todos los medios útiles. Dulcemente o rudamente, extraparlamentariamente o ilegalmente" 21 . Aunque con menos énfasis, las JP de Pierre Taittinger también hicieron gala de la misma lógica maximalista. Si bien se declaraban "por la propaganda, por la legalidad", como argüian, "no se discute con su médico sobre la urgencia y la natura de un medicamento mientras se está en la agonía". En consecuencia, "si la ceguera de nuestros adversarios fuera más fuerte que nuestra buena voluntad, si, poniendo el partido por encima de la Patria, rechazaran meditar y aplicar la única solución saludable, la nuestra, entonces, conscientes del peligro mortal que correría el país, empleariamos una acción más eficaz, de procedimientos más enérgicos"22.

La alergia al sufragio universal, al mandato de las urnas, explica la reivindicación del empleo de otros métodos para conseguir el poder. Los comicios eran un método caduco, un vestigio de tiempos decadentes: "la táctica ruinosa, absurda y siempre decepcionante de las buenas elecciones es agua pasada en esos ambientes de trabajo y de gran industria que durante tanto tiempo ha abusado de ellos."23. Frente a las fantasías románticas y artificiales, como gustaba decir a Maurras, se tenía que emplear la violencia: "la politica del buen juicio, la politica del golpe de fuerza sustituye el quimerismo electoral"24. A finales de 1926, delante de la disyuntiva sobre la participación electoral en el seno del partido fascista, Valois argumentó que "si hace falta votar, votaremos para la salud. ¿Pero dónde está la salud y cuál es su fórmula práctica?”. La respuesta era evidente a ojos de alguien que odiaba las urnas: "tomariamos parte, pero, en lo que nos concierne, no en un plano electoral" 25 . Formaciones contrarrevolucionarias más apegadas al sistema electoral como las JP no dudaban tampoco en desmarcarse convenientemente de los medios

20 Georges Valois, D’un siècle... op. cit., p. 243.

21 Georges Valois, "La Révolution nationale. Vers l'événement révolutionnaire", Le Nouveau Siècle, 21 de julio de 1926, p. 1.

22 "Notre doctrine. Pour l'ordre. Contre l'anarchie", F7 13232, en Archives Nationales de París (AN).

23 "Échos", L'Action française, 7 de diciembre de 1910, p. 1.

24 Charles Maurras, "Entre deux politiques”, L'Action française, 10 de mayo de 1910, p. 1.

25 Georges Valois, “Sur la route de Meaux. Cartes des Droites, Cartes des Gauches, ou?”, Le Nouveau Siècle, 30 de noviembre de 1926, p. 1. 
parlamentarios: "El derecho y el deber de las Jeunesses Patriotes está determinado a todo tipo de violencia, hacia el único objetivo de restaurar el orden en el país y en la República"26.

Para la contrarrevolución, el empleo de métodos fuera de la legalidad estaba plenamente justificado. "La violencia, la Revolución”, escribió Vaugeois, "no son más que medios"27. En reseñar la reinterpretación del mito de Antígona que hizo Maurice Barrès en Voyage de Sparte (1906), Lucien Moreau se preguntó "si algún tirano inepto o malvado, o sencillamente algún agente del extranjero lograra ampararse de ese poder sacrosanto, ¿no tendría el patriota rebelde contra el enemigo de la Patria el derecho de evocar las leyes no escritas contra las leyes injustas del tirano?"28. "La necesidad politica confiere al golpe de fuerza toda la majestad del derecho nacional", ya que, "para eliminar una absurda resistencia material", era necesario "llamar a la gran "partera de sociedades", a la fuerza", porque "lo que repudiará la insensatez parlamentaria, las espadas patriotas y racionales, las bayonetas inteligentes lo impondrán" 29 . Para defenderse de las acusaciones que les tachaban de inmorales por "estar decididos a sobrepasar los limites de la legalidad", los contrarrevolucionarios eran taxativos: "Hablamos de politica, exclusivamente de política", ya que la divisa "se guarda, pues, totalmente de la cuestión moral"30. La legitimidad del empleo de métodos ilegales se basaba en principios maquiavélicos: "El fin justifica los medios, todos los medios, jincluso los más deshonestos, los más pérfidos, los más abominables!". El razonamiento ontológico era sencillo. "La soberanía de la Salud pública" reemplazaba, según Léon de Montesquiou, "la Soberanía del pueblo, he aquí el hilo conductor"31.

El medio ilegal también se justificaba como un acto de legitima defensa en una situación agónica. De este modo, el empleo de la fuerza iba de la mano de la obsesión por la decadencia, de la paranoia de creer estar al borde del colapso. E1 pesar acerca del desfallecimiento nacional era una herencia directa de la pesadumbre pesimista de antiliberales como Édouard Drumont, cuyos lamentos son sintomáticos de la crisis finisecular ${ }^{32}$. No obstante, los contrarrevolucionarios no se limitarían a plañirse, ni a recrearse en la paranoia necrológica. Su actitud era la de despojar los males que carcomian la nación. Si "Francia se disuelve", era una obligación, aseveró Maurras desde el periódico, "querer combatirla por todos los medios"33. El mismo razonamiento de los nacionalistas integrales se

26 Informe del director de la Policía del Estado al secretario general del Ministerio del Interior, director de la Sûreté Générale, 19 de junio de 1926, París, F7 13233, en AN.

${ }^{27} \mathrm{H}[$ enri]. V[augeois]., "La Politique. Le Roi du Travail”, L’Action Française, 2 de mayo de 1909, p. 1.

28 Lucien Moreau, "Le voyage de Sparte", L’Action Française bi-mensuelle, 1 de junio de 1906, $\mathrm{n}^{\circ}$ $167,332-345$, pp. 333-334.

29 Charles Maurras, “À M. André Tardieu”, L’Action française, 3 de noviembre de 1910, p. 1.

30 Léon de Montesquiou, “Au jour le jour. Par tous les moyens”, L'Action française, 9 de junio de 1908 , p. 1.

31 Léon de Montesquiou, "Quelques textes pour nous prendre", L'Action française, 28 de diciembre de 1908, pp. 1-2.

32 Édouard Drumont, La fin d'un monde. Étude psychologique et sociale, Albert Savine, París, 1889, p. 251.

33 Charles Maurras, "L’Unité”, L’Action française, 12 de enero de 1909, p. 1. 
encuentra en la de las formaciones contrarrevolucionarias nacidas de la experiencia bélica. "Contra el peor Cartel resucitado", pedía vehementemente Taittinger, "la oposición debe estar unida, resuelta a salvar el país con todo y por todos los medios"34. "Toda la nación, de la ciudad a la gran sociedad anónima", lamentaba Valois, "está podrida por la elección democrática". El remedio a esa gangrena, a esos principios parlamentarios que "hacen morir todas las naciones", no era otra que "dar a Francia un gobierno que tomará el poder como podrá, por una operación legal, ilegal o extralegal”35.

\section{UNA TÁCTICA PARA UNA ESTRATEGIA MODERNA: LA NATURALEZA DE LA SUBVERSIÓN CONTRARREVOLUCIONARIA}

El objetivo de la contrarrevolución es suficientemente conocido. En 1908, Maurras declaró que "trabajamos para derrocar, por todos los medios", "el régimen qui existía en el momento del Afer Dreyfus y que aún existe"36. Más de quince años más tarde, Valois expuso "la operación por la cual los combatientes, bajo el mando de un jefe nacional, apoyados por una élite intelectual, burguesa y obrera del país, derrocarán el Estado liberal, suprimirán sus instituciones políticas, económicas y sociales y construirán el Estado nacional con sus instituciones propias"37. En Si le coup de force est posible, los autores descartaban un complot a modo de los de Monk o Tayllerand porque "toda acción, por sorpresa, se ha convertido en una quimera"38. La gran característica de la concepción del golpe de fuerza es que se alejaba del modelo de los pronunciamientos militares decimonónicos. Daudet lo describió perfectamente en una de sus editoriales:

No pretendo convencer a los pobres hombres timoratos que rondan el espectro del complot, la Alta Corte y otras absurdidades, que se imaginan que la victoria no exige ni lucha auténtica, ni esfuerzos reales, ni sacrificios. Estos parloteos de viejas mujeres ya no sirven. Con una generación nueva y tropas frescas, se prepara verdaderamente el asalto al régimen infame por los combatientes. Es a ellos a los que me dirijo ${ }^{39}$.

Para derrocar un régimen se requería algo más que un despacho oscuro y unos corazones soñadores. "Digo la politica del golpe de fuerza", concretaba en la misma línea Maurras, "porque sólo los niños grandes supondrían que el afer se reduce al triunfo de una conspiración de la casualidad"40. Del mismo parecer era Georges Valois. Dos décadas más tarde, escribiría que "tengo por absurdos, en el siglo XX, en Francia, los complots, las conspiraciones y las revoluciones bajo la

\footnotetext{
34 Pierre Taittinger, "Le salut par tous les moyens", La Liberté, 31 de octubre de 1925, p. 1. 26.

35 Georges Valois, La politique de la victoire, Nouvelle Librairie Nationale, París, 1925, pp. 25-

36 Charles Maurras, "Pour le "Clergyman"”, L’Action française, 23 de marzo de 1908, p. 1.

37 Georges Valois, La Révolution nationale, Nouvelle Librairie Nationale, París, 1924, p. 162.

38 Charles Maurras y Henri Dutrait-Crozon, "Si le coup de force est possible", L'Action française bi-mensuelle, $\mathrm{n}^{\circ} 206,15$ de enero de 1908, 131-160, p. 143.

39 Léon Daudet, "Remerciements", L’Action française, 6 de enero de 1909, p. 1.

40 Charles Maurras, “Entre deux politiques”, L'Action française, 10 de mayo de 1910, p. 1.
} 
forma de golpes militares. Esto me parece un cúmulo de baratijas históricas" ${ }^{41}$. La conquista de la opinión era capital para asegurar el triunfo. "La fortuna del Golpe de Fuerza depende del vigor y de la calidad de este movimiento de opinión", aseveraba Maurras ${ }^{42}$. "Es necesario, ante todo, organizar el estado de ánimo para facilitar el golpe, ver el golpe", señalaban los nacionalistas integrales, "nunca perderlo de vista mientras se trabaja con todo nuestro ahínco a organizar los ánimos". ${ }^{43}$ Por esta razón, la liga realista encaminaba los ánimos "a sugerir, a suscitar, a secundar un golpe, un golpe de fuerza: un golpe de fuerza dirigido contra el régimen que mata Francia". "El golpe", recordaba el provenzal, "no es posible más si se dispone de la opinión, hace falta conquistarla y, para conquistarla, imponer nuestra doctrina"44. En tanto que dirigente del partido fascista, Valois tenía claro que emprender cualquier acción requería de un proselitismo enérgico: "doblemos, tripliquemos, decuplemos los medios del periódico y del movimiento"45.

En empeño vertiginoso por la propaganda iba destinado a atraer a las multitudes. Las masas, ese objeto social que pasó a convertirse en un sujeto político después de la crisis de fin de siglo, eran indispensables para lograr el asalto al poder. Prueba de ello es que Daudet animaba a aunar diferentes sensibilidades: "estamos convencidos, además, que los elementos antisemitas, antidreyfusards, nacionalistas que se conjugaron hace ocho años en una tropa intensa pero desorientada, existen hoy, pueden ser reformadas, reagrupadas y lanzadas por la vía recta, por la vía verdadera, por la vía del Rey"46. "Somos en la época donde", recalcó el dirigente fascista, "los medios de organización y la acción deben ser reunidos y puestos en marcha"47. Un año más tarde, Valois describió gráficamente la importancia de articular un movimiento de masas cuando se refirió a su acción como un "hacer el frente nacional contra el Parlamento"48. Para ver hasta qué punto era importante gozar de apoyos sociales, Daudet incluso hizo un llamamiento "para esta obra necesaria y urgente, a todos los ciudadanos, incluso diputados, también senadores, de buena voluntad"49. Al referirse a la experiencia fascista italiana, Taittinger señaló que la clave del éxito del movimiento era haber sido capaz de aglutinar "hombres de derecha, de izquierda,

41 Georges Valois, L'Homme contre l'Argent. Souvenirs de dix ans, 1918-1928, Nouvelle Librairie Nationale, París, 1928, p. 57.

42 Charles Maurras, “Entre deux politiques”, L'Action française, 10 de mayo de 1910, p. 1.

43 "Ligue d'Action Française. Section ornaise”, L'Action Française, 19 de abril de 1908, p. 2.

44 Charles Maurras, "Notre congrès”, L’Action Française, 1 de junio de 1909, p. 1.

45 Georges Valois, "La Révolution nationale. Notre journal et nos moyens d'action", Le Nouveau Siècle, 5 de agosto de 1926, p. 1.

46 L[éon]. D[audet]., “La Politique. Le Réveil nationaliste”, L’Action française, 30 de marzo de 1908, p. 1.

47 Georges Valois, "Pour l'organisation et l'action”, Le Nouveau Siècle, 22 de octubre de 1925, p. 1 .

48 Georges Valois, "Sur la route de Meaux. Le Front nationale contre le Parlement”, Le Nouveau Siècle, 3 de octubre de 1926, p. 1.

49 Léon Daudet, “Les quinze mille et les trente mille”, L’Action française, 14 de octubre de 1908, p. 1 . 
de extrema-izquierda, de italianos que no querian morir"50. Por su lado, el paroxismo de la transversalidad en la articulación de un movimiento nacional que legitimara la transformación se encuentra en la voluntad del líder del Faisceau de colmar "la satisfacción de los electores y de los no-electores"51.

Fuera bajo la denominación "la revolución realista"52 o de "revolución nacional"53, ambas concepciones no desdeñaban el empleo de la ilegalidad más brutal. Esta idea fue fielmente expuesta por Camille Aymard: "es por la violencia que la revolución triunfa. Es por la violencia igualmente que la autoridad se restablece" 54 . Sin embargo, por mucho que nacionalistas integrales y fascistas emplearan el término revolución para marcar distancia con los pronunciamientos arcaicos, sería un error considerar la subversión contrarrevolucionaria de la misma naturaleza que el acto revolucionario. "La diferencia esencial entre la revolución y el golpe de fuerza", afirmó Daudet con una metáfora quirúrgica, "es que la revolución se dirige tanto a los miembros como a la cabeza, exige consecuentemente heridas múltiples y sangrantes, provoca sobresaltos $\mathrm{y}$ contradicciones dificiles de calcular de antemano". En cambio, el golpe de fuerza era una "operación decisiva y también una operación limitada que comporta el mínimo de daños"55. No obstante, la insurrección nacional no era una "Revolución mortífera e inútil", como tildaba Taittinger el modelo de "nuestros adversarios que abogan por la guerra de clases"56, sino una transformación limpia, medular, eficaz. Valois describió la toma de poder como un acto donde "se sustituye un gobierno que fracasa o que está del todo por debajo de la situación" 57 . Con esta idea fija, dirigió el asalto al estado en 1926 como un ejercicio de sustitución: "la Asamblea de Meaux será, en un plano extraconstitucional, el nuevo órgano de representación nacional"58.

En la mentalidad contrarrevolucionaria, la preservación del orden era esencial. Una revolución traía consigo la anarquía, "la imposibilidad de la producción"59. Comentando la insurrección republicana en Portugal de 1910, Maurras aclaró las diferencias con su concepción del golpe de fuerza. Pese a que "la verdad táctica es igual para todos" y que la insurrección fue hecha "por los

50 Discours du général Défontaine, de Me Roger Guérillon et Pierre Taittinger, vice-président de la Ligue des patriotes. Auxerre, 20 décembre 1925, Imprimerie Moderne, Auxerre, s. d., p. 13.

51 Georges Valois, "Avant notre Congrès. La crise politique, la crise économique, la période électorale", Le Nouveau Siècle, 17 de enero de 1927, p. 1.

52 Jules Lemaître, "Lettres à un ami. VI. Le Roi et la noblesse", L’Action française, 24 de marzo de 1909, p. 1.

53 Georges Valois, La Révolution nationale... op. cit., p. 162; Camille Aymard, Bolchevisme ou fascisme?... Français, il faut choisir!, Flammarion, Paris, 1925, p. 2005.

54 Camille Aymard, Bolchevisme... op. cit., pp. 283-284.

55 Léon Daudet, “Si le coup de force est possible”, L’Action française, 15 de abril de 1910, p. 1.

56 Pierre Taittinger, Les Cahiers de la jeune France, Éditions du National, París, 1926, p. 20.

57 Georges Valois, "Sur la route de Meaux. Pour l'action décisive”, Le Nouveau Siècle, 19 de septiembre de 1926, 2-3, p. 2.

58 Georges Valois, “Le Parlement à la cravache»”, Le Nouveau Siècle, 27 de noviembre de 1926, 2-3, p. 1 .

59 Georges Valois, La Révolution sociale ou le Roi, Nouvelle Librairie Nationale, París, 1911 [1907], p. 28. 
ritos que hemos expuesto", "Portugal no ha hecho una revolución para su orden interior ni para su grandeza nacional"60. Mientras que en Lisboa "un golpe de fuerza se ha cometido contra el orden", "el de la Action française será por el orden". La liga realista, puntualizaria, "hace verdaderamente acción y no agitación"61. Durante una de sus coyunturas más subversivas, Taittinger hizo el mismo apunte: las JP no actuaban como reacción, sino que empleaban la "acción, simplemente acción, acción inmediata"62. A diferencia de la revolución social, el golpe contrarrevolucionario era un acto tanto proactivo como reactivo. Para los realistas, la subversión significaba eliminar "el Orden republicano, es decir, extranjero, judio" para imponer "el Orden histórico de Francia, el Orden real"63. Para los fascistas, la revolución nacional se hacía en nombre del "nuevo orden"64. La insurrección contrarrevolucionaria no era una reacción. "El pasado es la Revolución", divulgaban los realistas, "y el futuro, por los franceses, como el presente, es la Monarquía"65. Pero, a su vez, también era un mecanismo de salvaguarda de un orden nacional telúrico. Con su obra, las JP pretendian "barrar el paso a la revolución preparada por la chusma de la sociedad francesa y tolerada por el gobierno"66. No en vano, Taittinger afirmó que "organicé las Jeunesses Patriotes para hacer de policia en las calles"67.

\section{LA NACIÓN MOVILIZAdA POR LA GUERRA. LA TOMA DEL PODER POR SUSTITUCIÓN (1916-1921)}

En una carta del 19 de diciembre de 1916, Georges Valois, combatiente en Verdún, hizo partícipe a Maurras de su idea de golpe. En la misiva, le proponía "llamar un gobierno al lado del gobierno existente". En lo que es una confidencia con mucha enjundia, se puede palpar el modelo primigenio de levantamiento contrarrevolucionario que a partir de entonces siempre defenderia: una insurrección nacional con un movimiento organizado con todos los elementos sociales representados y capaz de sustituir las instituciones vigentes. El "comité dictatorial" estaria formado por "algunos hombres tomados del Comité des Forges, del Sindicato de Armadores, tres o cuatro hombres muy representativos de los grandes intereses nacionales, tres o cuatro hombres a quien imagino que diriais: no tienen el derecho de no hacer nada". Con este "comité de organización nacional", haría falta reunir los jefes de las asociaciones comerciales, financieras, industriales y agrícolas e invitarlos a prevenirse contra "una movilización civil que

\footnotetext{
60 Charles Maurras, “Le sens politique»", L'Action française, 11 de octubre de 1910, p. 1.

61 Criton [Charles Maurras], "Revue de la Presse", L'Action française, 2 de noviembre de 1910,
} p. 3.

62 Pierre Taittinger, Les Cahiers... op. cit., pp. 87-89.

63 H[enri]. V[augeois]., "La Politique. La revolution pour l'ordre”, L'Action française, 17 de octubre de 1908, p. 1.

64 Georges Valois, "Sur la voie glorieuse et rude de la pauvreté et de la réussite", Le Nouveau Siècle, 29 de mayo de 1927, p. 3.

$65 \mathrm{H}$ [enri]. V[augeois]., "La Politique. Le rhéteur qui retarde", L’Action française, 12 de octubre de 1909 , p. 1.

66 Informe del 9 de enero de 1926, París, F7 13208, en AN.

67 Informe del prefecto de la Loira-Inferior al Ministro del Interior del 25 de junio de 1925 , Nantes, $F^{7} 13208$ en AN. 
lo pondrá todo patas arriba" y a "realizar ellos mismos la organización de la nación". El objetivo era "hacer entrar todos los franceses en el marco de una organización profesional con el fin de determinar sus posibilidades de trabajo"68. Debido a la guerra, suponía el conspirador, el plan tenía más guisos de triunfar. A grandes trazos, el esquema confiado a Maurras ya daba muestras de la mente preclara de Valois. Su esbozo de subversión no se limitaba a un chispeo, a un fuego de artificio, sino que iba un paso más allá. Se trataba de una toma de poder moderna, con respaldo nacional.

La relevancia histórica de Valois como vigorizador de la contrarrevolución se pone de manifiesto con una fuerza inaudita cuando se contrasta su desempeño insaciable con la actitud de sus compañeros realistas en la coyuntura histórica que se abrió con la conflagración. El plan insurreccional que diseñó fue urdido en unas circunstancias tan particulares como inéditas para la AF, cuya posición dio un vuelco rotundo con el estallido de la guerra: la formación pasó de pugnar contra el régimen a avalarlo a través de la adaptación del discurso antiliberal a la urgencia de preservar el bien nacional. Con convicción y solemnidad, Maurras no titubeó en afirmar que "frente al Extranjero amenazador, ya no hay partidos, hay la Patria"69. El acercamiento, aunque se vendiera como un acto de patriotismo por las circunstancias bélicas, molestó a algunos cuadros, los cuales abandonaron la formación. La policia se hizo eco del estado de ánimo pesaroso al notar que la liga "parece convertirse, esperando algo mejor, en un refugio de descontentos"70.

Tras el armisticio, la liga parecía haber recuperado la ambición de asaltar las calles. En 1922, L'Étudiant français, el órgano mensual de las juventudes realistas impulsado un año antes, proclamaba que "el momento llama a la acción" y que los hombres que eren necesarios no eran los de una "tropa de buenas voluntades", sino el de un "ejército disciplinado y decidido"71. En el periódico se seguian atentamente las dinámicas transnacionales hacia los golpes de estado y las tentativas de erradicar los gobiernos democráticos. En una pequeña nota donde se reflexionaba sobre los acontecimientos en España y en Italia, Maurras aclaró que "ni Mussolini ni el general de Rivera juegan a los césares; ellos "restablecen" la monarquía"72. La simpatía por las dictaduras en los estados mediterráneos se hacía extensible incluso al intento de toma de poder por parte de un grupúsculo de insurrectos völkisch en la República de Weimar. Sobre el putsch fallido de Múnich, los realistas comentaron que la intentona demostraba el "desdén en que ha caído el régimen republicano"73. En este contexto convulso,

68 Carta de Georges Valois a Charles Maurras del 19 de diciembre de 1916, 576 AP 69, en AN.

69 Charles Maurras, "La Politique. I. Nos deux devoirs”, L'Action Française, 27 de juliol de 1914, p. 1.

70 “À l’Action française”, 27 de abril de 1915, F7 13195/2, en AN.

71 “Chronique de nos groupes. Paris et Fédération des Étudiants d'A.F.", L'Étudiant français, $\mathrm{n}^{\circ}$ 3, diciembre de 1922, p. 58.

72 G. D., "Revue de la Presse. Commentaires français", L'Action française, 16 de septiembre de 1923, p. 2.

73 G. D., "Revue de la Presse. L'Allemagne et la démocratie”, L'Action française, 26 de noviembre de 1923 , p. 3. 
en un claro ejemplo de los límites de la desmovilización europea ${ }^{74}$, Valois replanteó lo que expuso en 1916. Desarrollando las líneas maestras del asalto al poder que había imaginado en las trincheras de Verdún, impulsó Confédération de l'Intelligence et de la Production Française (CIPF) en 1920.

La CIPF era un órgano con el que quería hacer una llamada a "los productores para la conquista del futuro"75. El organismo seguía el modelo de colaboración nacional que había expuesto por carta al provenzal: unir todas las fuerzas sociales de la nación en una estrecha colaboración en una situación económica delicada. Como aclararía años después en La Politique de la victoire (1925), ya fuera de la organización en la que concibió este modelo de golpe, "uno se puede apoderarse del Estado por un golpe de fuerza. Pero, hecho el golpe de fuerza, hace falta realizar una verdadera revolución"76. Sin embargo, el modelo de subversión no pasó de la fase conceptual. Para ello, requería "estar listos para tomar el Estado en el momento en que el Parlamento colapsará". Esto implicaba "preparar organismos técnicos con los sindicatos y los jefes de empresa, quienes son poco dados a la acción; coaligarlos al invitarlos a defender sus precios y el franco-oro" y "construir organismos intersindicales e intercorporativos para tener entre las manos órganos de mando de la vida económica"77.

Sin embargo, los exabruptos no iban de la mano de una práctica positiva. Aunque Maurras declarara que "si un golpe de fuerza para instaurar el rey se hubiera producido en 1912, la inmensa mayoría del pueblo francés no habría experimentado que un movimiento de curiosidad indiferente", pero que ahora, no obstante, "la situación se ha revertido" 78 , los aires que se respiraban en la calle Rome no eren golpistas. El claro ejemplo era Daudet, quien afirmó que el error republicano "es tan manifiesto que me pregunto si la fórmula del golpe de fuerza no es inútil", ya que "me he convencido, en efecto, que, dentro de dos años, tres como máximo, los hechos abrirán los ojos más reacios a la verdad"79. Con este comentario se evidenciaba que la liga realista se había acomodado en el juego electoral. En sus memorias, Louis Dimier justificó su marcha porque "la guerra hizo recular nuestro proyecto"80. Incluso Jacques Bainville cayó en un cierto pesimismo al ver que en los estados vecinos se ensayaban formas autoritarias y dictatoriales $^{81}$. El sentir de Valois también se alejaba del acomodo que envolvía la mayor parte de sus compañeros. A pesar que justificara la aventura electoral de

74 John Horne, "Smobilitazioni culturali dopo la Grande Guerra 1919 - 1939", Italia contemporanea, 1999, $\mathrm{n}^{\circ} 215,331-339$.

75 Georges Valois, "L'Économie nouvelle. La Confédération de l'Intelligence et de la Production française. Son esprit et ses méthodes d'organisation", L'Action française, 29 de marzo de 1920, p. 4.

76 Georges Valois, La politique... op. cit., p. 26.

77 Georges Valois, L'Homme contre... op. cit., p. 58.

78 “Aux Sociétés Savantes. Le VII Congrès National d'Action Française. Le rapport de Charles Maurras", L'Action française, 19 de març de 1920, p. 2.

79 "La séance d'ouverture du VII Congrès d'Action Française. Le discours de Léon Daudet. Après cinq ans de guerre. Le pilote nécessaire: le Roi”, L'Action française, 18 de marzo de 1920 , p. 1 .

80 Louis Dimier, Vingt ans d'Action Française, Nouvelle Librairie Nationale, París, 1926, p. 304.

81 Jacques Bainville, “30 d'octubre de 1922”, en Journal, vol. II. 1919-1926 (3 vols.), Plon, París, 1949 (1948-1949), pp. 160-162. 
1919 con el argumento que "esos hombres llevan, al Parlamento, la luz de su doctrina construida sobre el interés general"82, tenía claro que, para la reconstrucción de Francia, hacian falta métodos excepcionales. Frente a un régimen parlamentario que "hace como el avestruz", insistía en que "para aplicar las soluciones, se tendrán que aplicar métodos dictatoriales que no se osa ni imaginar"83.

\section{MATERIALIZAR LA SUSTITUCIÓN. LA CAMPAÑA CONTRA EL PARLAMENTO (1922-1924)}

A fin de proseguir con su plan para asaltar el poder, Valois planificó lo que vendría a ser una gran campaña de desprestigio del parlamento. "El método será provocar un movimiento por los Estados generales antes que la Action française haya dicho nada" para, "un año más tarde", presentarse como su gran aval. Como pondría de relieve, se trataba de dar la imagen que "el movimiento por los Estados generales nació 'espontáneamente' por el país" ${ }^{4}$. La puesta en escena tuvo lugar en la Sala Wagram de París el 18 de diciembre de 1922, cuando anunció la campaña con un vivaz: "nos opondremos por todos los medios a la bancarrota fraudulenta por emisión del papel-moneda, de la falsa moneda"85. El núcleo de su táctica continuaba siendo el mismo que había urdido el 1916 y que había impulsado con la CIPF: aglutinar las fuerzas vivas de la nación con el objetivo de suplantar el modelo parlamentario actual. Por esa razón, quería atraer el grueso de obreros e industriales, vertebrar un movimiento transversal con base sindical-corporativo con el fin de instaurar una institución que hiciera de contrapeso al parlamento: "la Corporación deberá ser llamada por el Estado a resolver sobre todas las cuestiones económicas de su competencia"86. La idea principal era "coordinar todos los esfuerzos, dirigir por niveles todos los grupos de interés a la federación y plantear la cuestión al Parlamento para obligarlo a reformarse o a desaparecer"87.

"Este pueblo está cansado, listo para rebelarse", anunciaban los miembros del comité. Desde la redacción de la revista oficial de los Estados Generales, los convocantes aseguraban que "no nos metemos aquí bajo el simbolo de la violencia, sino bajo el símbolo de la Razón y de la Fuerza unidas". No obstante, alertaban que "ciertas palabras no nos pueden asustar"88. En la línea de actuación que era propia a Valois, "no se trataba de provocar una agitación en el país", sino de plasmar todas esas "iniciativas de reformas que se han producido

82 Georges Valois, "L'Action française au Parlement et la victoire économique", L'Action Française, 10 de noviembre de 1919, p. 4.

83 Georges Valois, “Des périls ou l'État met la production française" (L'Action Française, 22 de septiembre de 1922), Le Point. L'État et la Production, Nouvelle Librairie Nationale, París, $1922, \mathrm{p}$. 33.

84 Georges Valois, L'Homme contre... op. cit., p. 70.

85 “Origines de la campagne pour les État Généraux", Les Cahiers des États Généraux, n 1 , abril de 1923, 78-92, p. 90.

86 Eugène Mathon, "La Corporation, Pierre angulaire des états professionnels", Les Cahiers des États Généraux, $\mathrm{n}^{\circ} 1$, abril de 1923, 34-55, p. 49.

87 Georges Valois, L'Homme contre... op. cit., p. 59.

88 La Rédaction, “Avant-propos”, Les Cahiers des États Généraux, n 1, abril de 1923, 5-8, p. 7. 
fuera del Parlamento". El asalto al poder se ejecutaría, una vez más, a través de una sustitución: "el movimiento debe dirigirse no hacia la destrucción de una institución existente, sino hacia la creación de una institución nueva que proveerá al Estado de apoyos nuevos por todo el país"89. Esta idea era importantísima porque daba un aura de legitimidad a una iniciativa que reunía también a republicanos y que iba enfocada a recibir el soporte de las élites económicas tanto industriales como sindicales. Al presentar su proyecto como una exigencia popular en clave nacional, les servía tanto de justificación para la empresa como de pretexto para erosionar el funcionamiento del régimen: "por un lado, un pueblo donde la energía abunda y que busca organizarse, por el otro, un Estado débil, asfixiado por las pasiones, de las pequeñeces, por los movimientos mismos del pueblo sumidos en el error"90.

El método de asalto al poder se planteaba por medio de una insurrección extralegal. Una de las mayores críticas que refutaban la idoneidad de la iniciativa era la duplicidad de instituciones. "Poned frente a frente estos dos Parlamentos, uno legal, el otro extra-legal" e inevitablemente, advertían los opositores, "entraran en lucha" 91 . La cuestión de cómo ejecutar el reemplazo ya fue apuntado por Ambroise Rendu, que afirmó que "uno de los esfuerzos principales de los Estados será el reconocimiento legal de su situación de hecho". Mientras pugnaban en el vacío legal, "ellos existirán conforme a la ley sobre las asociaciones". Con desfachatez, apuntaban que, "además, su actividad podrá beneficiar los grupos profesionales con unas ampliaciones considerables aportadas al derecho sindical por la ley de 1920"92. Evidentemente, el terreno en el que Valois se planteaba operar no era el del juego liberal: "no es al Parlamento donde iremos, ya que el Parlamento es la expresión de los partidos. No nos emplazaremos en los que se denomina el terreno de las opiniones, ya que es allí donde nos dividimos en partidos". Con pretextos como "los Estados Generales serán un poder auxiliar, no un contra-parlamento" 93 , el excombatiente intentaba disimular la carga subversiva de un golpe que pretendia "tomar el mando de los franceses que se verán desasociados del Estado" gracias a la preparación previa de "órganos de mando" 94 . Le Temps dedujo bien los subterfugios de la subversión disimulada que se planteaba cuando afirmó que "la ida general es siempre -como en tiempos de las grandes campañas antiparlamentarias de antaño- de llamar a la nación por encima de la cabeza de sus representantes políticos"95.

89 Eugène Mathon, Étienne Bernard-Précy, Max Leclerc, Bernard de Vesins, Paul Robain, Auguste Cazaneuve, Eugène Martin-Mamy, Georges Coquelle, Ambroise Rendu, Georges Valois, "La Réforme de la répresentation devant l'État. Programme du Comité d'Action", Les Cahiers des États Généraux, n 1 , abril de 1923, 9-22, p. 12.

90 J[acques]. A[rthuys]., "Historique du mouvement des États Généraux", Les Cahiers des États Généraux, $\mathrm{n}^{\circ} 1$, abril de 1923, -33, p. 33.

91 L. L. “Opinions de Province”, Le Temps, 13 de marzo de 1923, p. 1.

92 Ambroise Rendu, "Pour la constitution des États de la région Languedoc-GascognePyrénées”, Les Cahiers des États Généraux, n² 2, 15 de mayo 1923, 119-135, p. 133.

93 Georges Valois, "Réponse au "Provincial" et à quelques contradicteurs de Paris et de province", Les Cahiers des États Généraux, n 2, 15 de mayo 1923, 144-153, pp. 145 y 148.

94 Georges Valois, L'Homme contre... op. cit., p. 70.

95 "«États-Généraux", Le Temps, 12 de abril de 1923, p. 1. 
El desarrollo del golpe de fuerza siguió acorde al esquema que presentó a Charles Maurras: “prepararemos el movimiento por las Semanas y los Comités. En el momento dado, lanzaremos la idea sin descubrirnos. Haremos que sean otros los que hablen. Seis meses más tarde, tomaremos la cabeza del movimiento"96. Con todo, la insurrección no llegó a culminarse; no se concretó ninguna organización de intereses y, por ende, no se produjo un asalto al poder. Una vez más, el motivo ulterior que explica el fracaso del asalto al poder se encuentra en los obstáculos internos que tuvo que afrontar Valois. Según relata, su plan estuvo boicoteado desde el interior por algunos miembros del comité para la convocatoria de los Estados Generales ${ }^{97}$. Además, tampoco ayudaba que sus compañeros de la AF tuvieran las elecciones de 1924 como gran objetivo. En las memorias escritas después de la separación con la liga, Valois calificó la aventura electoral de ser "completamente absurda"98. El estrepitoso naufragio en las urnas llevó a Lucien Rebatet a separarse de la formación porque "la República había hecho con las urnas el censo preciso de sus fieles"99. A colación de los malos resultados electorales, el periodista Louis Latzarus se hizo eco de la improbabilidad del éxito de una restauración monárquica. Pese a ver factible aún la ejecución de un golpe, se mostraba del todo escéptico a su desarrollo: "el día después del golpe de fuerza es imposible"100. Los realistas le respondieron invitándole a ir a provincias, donde "el elector se irrita, se aleja de los apóstoles del inmovilismo y se dirige hacia aquellos que tienen el aspecto de querer hacer algo"101. Pero como sentenció Albert Thibaudet, crítico literario y analista perspicaz, "las ideas politicas de Maurras son ideas de poeta, empezando por la principal, la idea del rey"102.

Por mucho que los nacionalistas integrales se rasgaran les vestiduras, a la altura de 1925 se había puesto de manifiesto una verdad dolorosa: la hegemonía de la liga se veía contestada por nuevas formaciones con un espíritu más en consonancia con las inquietudes de los que vivieron de primera mano la masacre mundial. La Légion de Antoine Rédier o las JP de Pierre Taittinger, las cuales se unirian posteriormente, son el ejemplo más ilustrativo de que ya no todos los caminos de la contrarrevolución pasaban por la calle de Rome. En esta tesitura, Valois intentó dar un vuelco a la situación. Tal y como declaró en 1928, "se tenía que ir más allá de los Estados Generales y entrar en una acción netamente revolucionaria"103. En sintonia con las nuevas formaciones contrarrevolucionarias, el veterano de Verdún vio en los excombatientes los

96 Georges Valois, L'Homme contre... op. cit., p. 70.

97 Valois se refiere a Bernard-Précy que llevó a romper la amistad que tenía con Eugène Mathon, industrial y principal avalador de la empresa. Georges Valois, L'Homme contre... op. cit., p. 91 .

98 Georges Valois, L'Homme contre... op. cit., p. 67.

99 Lucien Rebatet, Les décombres, Éditions Denöel, Parîs, 1942, p. 112.

100 Louis Latzarus, La France veut-elle un roi?, Editions du siècle, París, 1925, p. 139.

101 Georges Ollier, “À travers les Idées, les Revues et les Livres. Un républicain national”, L'Étudiant français, 1 de julio de 1925, p. 2.

102 Albert Thibaudet, "Une critique de jugement" (Nouvelle Revue Française, agosto de 1923), en Réflexions sur la critique, Gallimard, Paris, 1939, p. 140.

103 Georges Valois, L'Homme contre... op. cit., p. 101. 
agentes de la subversión: "Los Combatientes no son simplemente los antiguos combatientes de la guerra; son los hombres que tienen el espíritu de combatiente y que se ponen al servicio de la revolución nacional"104. El rol destinado a los veteranos era axial, tal y como lo demuestra que, en la presentación del Faisceau en la Salle d'Horticulture a finales de 1925, Valois se refirió al método de asalto al poder como "el método del combatiente"105.

\section{UN VERANO CALIENTE. UNA MARCHA QUE PARECÍA IMPARABLE HACIA EL ESTADO NACIONAL (1926)}

Ya como lider de su propia formación, Valois expuso que, a diferencia de la $\mathrm{AF}$, donde "nadie osa hablar de golpe de fuerza" porque el medio "se estaba convirtiendo en una quimera"106, él tenía verdaderamente un plan de subversión. La apuesta parecía clara: "La revolución nacional llama a un Jefe; ella provoca su instalación" y "él será quien tomará el mando de la revolución nacional"107. Bajo estas preposiciones, trabajó intensamente para articular un movimiento de masas transversal que fuera capaz de asaltar el poder. "Nuestro objetivo es la conquista del Estado para realizar una nueva organización política, económica y social y acometer el renacimiento francés", escribió con rotundidad en 1925. "Haremos esta conquista al mismo momento que se derrumbará o se desvanecerá el Estado parlamentario, completamente impotente para salvar las dificultades que lo desbordan de todos lados"108. Toda la tensión monetaria, financiera y social que siguió el armisticio y las negociaciones por la paz no podían sino culminar en un asalto al poder que permitiera reconducir la situación desastrosa que empujaba Francia al colapso: "El fin del drama es la llegada de un jefe nacional que pone fin a las disputas y al pillaje de los partidos"109

Con esta premisa en mente, esperando las circunstancias idóneas, la agenda del lider fascista pasaba por denunciar sistemáticamente las politicas monetarias del Cartel des Gauches a fin de poner en guardia a los franceses sobre la catástrofe financiera que se avecinaba. La primera manifestación de fuerza del movimiento tuvo lugar el 21 de febrero de 1926 en Verdún. La fecha escogida conmemoraba el décimo aniversario del ataque alemán. Como demostración de poderio, el despliegue fue bastante impactante ${ }^{110}$. Frente a 4.000 asistentes, se trataron seis puntos programáticos: "obligar a la abdicación del Parlamento"; "instaurar una dictadura nacional por encima de los partidos"; "organizar inmediatamente una verdadera representación de los intereses nacionales";

\footnotetext{
104 Georges Valois, La Révolution nationale, Nouvelle Librairie Nationale, París, p. 170.

105 Georges Valois, "Introduction. La politique de la victoire" (11 de novembre de 1925, París), La politique de la victoire, Nouvelle Librairie Nationale, 1925, VII-XXXII p. XIII.

106 Georges Valois, L'Homme contre... op. cit., p. 67.

107 Georges Valois, La Révolution nationale, Nouvelle Librairie Nationale, Paris, pp. 182-183.

108 Georges Valois, "Introduction. La politique de la victoire”, La politique... op. cit., p. XIV.

109 Georges Valois, "Introduction. L'Esprit de la victoire et la restauration financière en France" (Montlieu-Inxent-Paris, maig-juny de 1925), L'État, les finances et la monnaie. Étude sur le problème financier et monétaire de 1919 à 1925. OEuvre économique. II, Nouvelle Librairie Nationale, París, 1925, IX-XLIII, p. XXIX.
}

110 Nota del 23 de febrero de 1926, F7 13210, en AN. 
"resolver inmediatamente el problema financiero"; "organizar racionalmente la producción"; "coordinar todas las fuerzas francesas por medio de un Estado unitario para realizar la prosperidad y la grandeza por las cuales cuatro-cientos mil franceses murieron en Verdún"111. Dicho programa de mínimos parecía apuntar hacia una dirección concreta: el asalto al poder. El vocabulario evocaba a una tensión que podía estallar como un volcán.

La marcha hacia la revolución nacional parecia imparable. Unos meses después, tuvo lugar la segunda asamblea nacional en Reims. El 27 de junio, el Marne fue el escenario de "la agrupación orgánica de los productores", de "una revuelta de la nación contra el Estado parlamentario", como la describieron en los informes policiales. El temor de las fuerzas del orden se comprende porque el Faisceau estaba en pleno apogeo y el movimiento fascista gozaba de un momento de salud exquisito, con un crecimiento notable en la base militante ${ }^{112}$. La puesta en escena no era para menos: un desfile de camisas azules con el brazo en alto flanqueaba al líder fascista. En medio del frenesí, el orador concluyó el mitin animando a la audiencia a multiplicar el proselitismo porque "depende de vosotros, y de nosotros también y del trabajo de organización que haremos" cumplir con el gran objetivo de "la conquista del Estado". ${ }^{113}$ Frente al despliegue de fuerza del Faisceau, la AF quiso marcar territorio con la retórica belicista habitual. Por "el día del gran golpe", repitió grandilocuentemente Maurice Pujo, "tenemos tropas bien entrenadas"114. Georges Calzant, secretario general de los Étudiants, reivindicó el papel de sus jóvenes respecto a las del "traidor de Valois"115. Pero la situación evidenciaba que los ánimos del sector estudiantil de la liga eran más ardientes que las de la cúpula.

A finales de julio, la inercia positiva de la congregación en Reims parecía que encontraba una situación de congruencia con el escenario crítico que se anhelaba. La coyuntura era, para Valois, apocalíptica. El sentimiento era compartido por otras formaciones de extrema-derecha. Camille Aymard, redactor jefe de La Liberté, periódico oficioso de las JP, ponía en guardia al lector: "el país se encontrará enfrente de esta alternativa: de ser pasto de la bancarrota dentro del torbellino revolucionario o de estar obligado, para asegurar su salud, a recurrir al golpe de fuerza, con los riesgos que comporta un acto semejante de desespero"116. Aprovechándose de las circunstancias pesarosas de desequilibrio inminente, Valois concluyó con cinismo que sólo "quedaba la solución

111 "Faisceau des Combattants et des Producteurs. Le programme de Verdun", dins de F7 13209, en AN.

112 Nota de 13 de abril de 1926, F7 13208, en AN.

113 Georges Valois, "Septième résolution. L'appel aux combattants pour la création de l'État national", en Première Assemblée Nationale des combattants, des producteurs, et des chefs de famille tenue à Reims le 17 juin 1926, Nouvelle Librairie Nationale, París, 1926, 119-130, p. 127128.

114 “Au Quarter Latin. Le banquet des Étudiants d'A.F. Maurice Pujo", L'Action française, 10 de juny de 1926, p. 2.

115 “Au Quarter Latin. Le banquet des Étudiants d'A.F. Georges Calzant”, L'Action française, 10 de juny de 1926, p. 2.

116 Camille Aymard, "Sous la bourrasque", La Liberté, 18 de julio de 1926, p. 1. 
extraparlamentaria"117. Francia vivia "una situación revolucionaria", y la solución para hacer frente a la crisis venidera pasaba por que el parlamento se apoyase en "las fuerzas del país representadas por los comités económicos nacionales y sociales"118.

Los remedios teóricos iban acompañados de manifestaciones por las calles. La más sonora fue la del 21 de julio, cuando el gobierno de Édouard Herriot cayó. El dirigente fascista no dudó en atribuirse los méritos y proclamar que "el miedo al fascismo ha hecho nacer el gobierno de concentración parlamentaria"119. En medio del goce de ver caer la coalición de izquierdas mientras se ceñía una crisis en el horizonte, anunció que "convocamos la Asamblea de Meaux". Con impetuosidad, alentaba "que cada legionario reclute dos, tres, cinco camaradas" porque "la revolución no se hará en ocho dias", sino que "ella tendrá su jornada decisiva, pero habrá trabajo para diez años"120. Según comentaba, "el desencadenamiento será en una fecha próxima" y "el primer acto será naturalmente la toma del poder". "Para este primer acto, hace falta una preparación", y anunciaba que "la preparación está muy avanzada por nosotros mismo y por otros"121.

El anuncio reiterado de que el momento había llegado, que los requisitos sobre la catástrofe inminente eran palpables, terminaron en una desazón cuando los horizontes apocalipticos no se concretaron y las medidas aplicadas por el gobierno Poincaré empezaron a dar resultados. Encima, el movimiento se vio sacudido internamente justo en el momento en que el camino hacia la revolución nacional tenia que entrar en la tercera fase, con la reunión a Meaux ${ }^{122}$. Pese a que su formación, junto con la AF y las JP, encontraban simpatias entre militares y agentes del orden, no se podía contar con ellos para la sublevación ${ }^{123}$. Con los alborotos de julio se puso fin a la marcha hacia el poder que se habia iniciado en Verdún. Además, se cerró el ciclo de tentativas por parte de la contrarrevolución de dar un golpe de fuerza antes que la verdadera crisis sacudiera Francia a partir de la siguiente década. En esta primera fase contrarrevolucionaria, Georges Valois jugó un papel de primer orden, en tanto que teórico de la acción y hombre de organización, cuyos planes truncados o abortados resultan indispensables para reflexionar acerca de la concepción golpista de la contrarrevolución.

117 Georges Valois, "La crise politique. Contre la inflation", Le Nouveau Siècle, 19 de juliol de 1926, p. 1.

118 Georges Valois, "Une situation révolutionnaire”, Le Nouveau Siècle, 20 de julio de 1926, p. 1.

119 Georges Valois, "La Révolution nationale. Notre journal et nos moyens d'action", Le Nouveau Siècle, 5 de agosto de 1926, p. 1.

120 Georges Valois, "La Révolution nationale. Substitution de l'État national à l'État parlementaire", Le Nouveau Siècle, 21 de julio de 1926, p. 2.

121 Georges Valois, "La Révolution nationale. Vers l'événement révolutionnaire", Le Nouveau Siècle, 21 de julio de 1926, p. 1.

122 La llegada de Raymond Poincaré en el poder desbarató sus planes. Además, su posición interna en el partido se vio cuestionado por un lobby de agentes de François Coty, futuro fundador de Solidarité Française en 1933, magnate perfumista y dueño de la mayoría de cabeceras de derecha, quien había financiado Le Nouveau Siècle y quería hacerse con el control del partido. Ver: Georges Valois, L'Homme contre... op. cit., pp. 312 y 344.

123 Informe del 11 de enero de 1926, $\mathrm{F}^{7}$ 13208, AN. 


\section{CONCLUSIÓN: ¿POR TODOS LOS MEDIOS?}

Desde su génesis, la cultura política contrarrevolucionaria ha contemplado la insurrección como una táctica legítima para hacerse con el poder. Los nacionalistas integrales fueron los primeros en posicionarse abiertamente a favor de la subversión:

La Action française siempre ha dicho que el Gobierno existente seria muy probablemente derrocado -como la mayoría de gobiernos que lo han precedido- por la fuerza. La Action française siempre ha dicho que la preparación y la organización del Golpe de fuerza, como la constitución y difusión del estado de ánimo que debe permitir al golpe de fuerza triunfar, eran elementos esenciales de su programa ${ }^{124}$.

No obstante, las experiencias de Georges Valois en el seno del espacio contrarrevolucionario durante las primeras décadas del Novecientos ponen de manifiesto las complejidades que rodearon la concepción del golpe de fuerza. Georges Sorel fue de los primeros en poner en duda la capacidad de los nacionalistas integrales para llevar a cabo una acción transgresora fuera del plano de las ideas ${ }^{125}$. Más tarde, fue Valois quien describiría la teoría insurreccional que antaño le fascinó de no ser más que "verbalismo"126. Incluso los realistas, frente a los ataques del periódico alsaciano Elsasser que les acusaba de envidiar un golpe de fuerza como la marcha sobre Roma de Mussolini, responderían que "nos reímos de esta insinuación porque, habiendo desarrollado la solución que conviene a nuestro país, nuestros lectores saben que no nos mantenemos en esta solución"127. Lo mismo ocurriria a otras formaciones contrarrevolucionarias. Si bien un informe del comisario central al director de la Sûreté Générale sobre la Légion de Rédier subrayaba que, pese a "depender visiblemente de las tendencias de Millerand, Taittinger, de Castelnau”, pretendía dar "a las fuerzas de la oposición una organización comuna capaz de reacción violenta" 128 , las pulsiones insurreccionales no se concretaron en ninguna acción visible. Tras el colapso del Faisceau a principios de 1928, el mismo Valois revisaría su participación insurreccional en los acontecimientos de julio de 1926 y se desmarcaría de cualquier actitud de agitación subversiva129. Del mismo modo, las JP también jugaron a abstenerse. En una columna que reflexionaba sobre la crisis de julio de 1926, Aymard planteó que la subversión era un síntoma natural, una reacción lógica, legítima:

${ }^{124}$ L’Action Française, "Le coup de force”, Action française, 29 de diciembre de 1909, p. 1.

125 "No es únicamente con escritos que se derroca un régimen establecido", le comentaría el 17 de junio de 1910. En Jean Variot, Propos de Georges Sorel, Gallimard, París, 1935, p. 124.

126 Georges Valois, L'Homme contre... op. cit., p. 86.

127 Georges Havard de la Montagne, "Revue de la Presse. Inadmissible confusion", L'Action française, 21 de enero de 1923, p. 3.

128 Informe del 5 de marzo de 1925, Ruan, F7 13208 en AN.

$129 \mathrm{Su}$ versión tras la etapa fascista fue que la policia, bajo las órdenes de Herriot, habian suplantado sus hombres para dar rienda suelta al fantasma del golpe fascista: "Me quedé un poco sorprendido de no ver, entre las camisas azules, ningún rostro conocido, y de no ser saludado por nadie [...] Descubro que las camisas azules no eran camisas de prescripción. Eran camisas elegantes. ¿Los que las llevaban? No hay duda: eran empleados de la policía. La trampa estaba lista». En Georges Valois, L'Homme contre... op. cit., p. 257. 
Si se entiende por golpe de Estado la voluntad de poner fin a las tradiciones de impotencia y de anarquía del régimen; de enviar las cambras de vacaciones por algunos meses después de haberlas coaccionado, bajo amenaza de la disolución, a dar los plenos poderes a un gobierno fuerte, se puede decir que un golpe de Estado se hará solo, como el niño se encuentra disparado fuera de la matriz por el trabajo mismo de la naturaleza.

"La sola cuestión que se expone es de saber quién hará el golpe de Estado". La pregunta sin respuesta de Aymard ponía de manifiesto que, a pesar de las ansias para subvertir el régimen, se esperaba un hombre redentor que, se sobrentendía, no se encontraba entre sus filas: "Francia aclamará mañana el hombre -quien sea- que responderá a su llamada"130.

A menudo, la inconcreción a la hora de acometer el golpe convertía la subversión en un acto de fe escatológico que era motivo de escarnio. Metamorfoseando la liga realista en "La Volonté Franque" y los camelots en los "Mégottiers du Prince", Gyp no creía que se realizara el "Gran golpe tantas veces anunciado" porque a "la gente de La Volonté les falta decencia"131. En 1924, Berth, declaró que "los neomonárquicos son verdaderamente unos intelectuales exagerados que se imaginan poder restaurar una Francia monárquica solamente con el poder de la dialéctica"132. El periódico republicano L'OEuvre se burlaria de la proclama de la "politica de la victoria” de Valois con un “¡Bravo! Buena fórmula. ¿Qué significa?"133. Tampoco ayudaba que entre formaciones contrarrevolucionarias se acusaran de ser unos farsantes. Como disidente, el líder del Faisceau recriminó a la AF que "en veinte años, se tuvo el tiempo de preparar un golpe de fuerza. Hace veinte años que la Action française lo anunció. Ella no lo ha hecho"134. A su vez, sus antiguos compañeros se defendieron al recalcar que "Georges Valois nunca tuvo parte en la dirección de ningún golpe de mano de la Action française"135. Se referían al escindido como un "aprendiz de dictador"136, de un "charlatán" que "dice una cosa, hace otra y manda hacer una tercera"137. Taittinger acusó a los nacionalistas integrales de "intentar vanamente desde hace muchos años demoler el régimen"138. Los realistas se burlaban de "la

130 Camille Aymard, “De quoi demain sera-t-il fait?”, La Liberté, 24 de junio de 1926, p. 1.

131 Gyp [Sybille Riqueti de Mirabeau, condesa de Martel de Janville], La bonne fortune de Toto, Flammarion, Paris, 1926 [1911], pp. 43 y 167-168.

132 Édouard Berth, Guerre des Etats ou guerre des classes, Marcel Rivière, París, 1924 p. 313.

133 Jean Piot, "Le fascisme et la politique du "n'importe quoi"”, L'OEuvre, 12 de diciembre de 1925, p. 1.

134 Georges Valois, L'Homme contre... op. cit., pp. 60-61.

135 Charles Maurras, "La Politique. III. Une exécution", L’Action Française, 15 de diciembre de 1925, p. 1.

136 Léon Daudet, "Le cas extravagant de Georges Valois”, L'Action Française, 25 de diciembre de 1925, p. 1. También lo llamarían "dictador de madera". En ÍD., "La bourrique "Valois" en pleine lumière", L'Action Française, 3 de abril de 1926, p. 1.

137 Charles Maurras, "La Politique. IV. Sur un charlatan”, L'Action Française, 27 de diciembre de 1925 , p. 1.

$138 \mathrm{H}$ [enri] de K[érillis], "La politique des Jeunesses patriotes", L'Écho de Paris, 3 de diciembre de 1928 , p. 1. 
estupidez de ciertas consignas"139 electorales de las JP y, en diciembre de 1928, frente a un nuevo giro legalista de la formación, espetaron con malicia que Taittinger quería "reinventar el oportunismo"140.

Los sarcasmos y los comentarios desdeñosos son indicativos de que no existe una correlación directa entre la violencia desplegada en las calles contra enemigos/rivales políticos con que el asalto al poder tuviera que producirse irremediablemente mediante prácticas violentas. Con todo, las burlas y las recriminaciones no deben desvirtuar la naturaleza de una cultura política cuyo mayor anhelo era tomar el poder para terminar con la modernidad liberalcapitalista que tanto odiaban. Son numerosas las reivindicaciones de los nacionalistas integrales para "luchar contra esta Golfa de Ruina Pública"141. En 1925, Valois declaró con pesadumbre desde su periódico que "el Estado liberal reina, imposibilitando toda dictadura nacional, pero imponiendo la dictadura del Partido a la nación"142. Al mismo tiempo, Taittinger apuntaba que "no son golpes de navaja, sino golpes de hacha lo que se necesita para cortar sus tentáculos"143. Los ataques y acusaciones entre formaciones deben servir para recordar que las tres organizaciones estaban en disputa por la ascendencia de un espacio contrarrevolucionario que pregonaba aciagamente el derrumbe del sistema. Con la fundación del Faisceau, algunos jóvenes camelots se fueron con Valois ${ }^{144}$. Rédier abandonó las JP para pasarse a la nueva formación ${ }^{145}$. Antes, ya había habido flirteos entre camelots con la formación de Taittinger ${ }^{146}$.

El problema de fondo es que se ha tendido a hacer una lectura muy restrictiva de la premisa contrarrevolucionaria de "por todos los medios", cuando, más bien, el significado se debería tomar en su sentido más literal. En parte, la confusión se debió a los mismos interesados, quienes acentuaban el cariz radical de su apuesta subversiva: "para hacer la Monarquía, todos los medios son buenos. Solamente los ilegales son eficaces"147. Sin embargo, la actitud subversiva podía ejecutarse tanto bajo la forma de un golpe ilegal como de una acción legal. No se debe olvidar que la AF fue concebida primigeniamente en vistas a las elecciones de 1906148. Como recordó Maurras, "más de una propaganda electoral ha sido eficaz", a condición que "ella debe secundar el

139 "Revue de la Presse. Les partis d'ordre aux éléctions", L’Action Française, 4 de diciembre de 1927 , p. 5.

140 N. S. A., “Au Quartier Latin. La réunion de rentrée des Étudiants d'Action Française. Gabriel Jeantet”, L’Action Française, 12 de diciembre de 1928, 1-2, p. 2.

141 "Ligue de 1'Action Française. Nos réunions et nos sections. Roubaix", L'Action française, 7 de abril de 1909, p. 2.

142 Georges Valois, "Introduction” (Montlieu-Inxent-París, mayo-junio de 1925), L'État, les finances et la monnaie, Nouvelle Librairie Nationale, París, 1925, IX-XLIII, p. XXIII.

143 Pierre Taittinger, Les Cahiers... op. cit., p. 85.

144 Informe del 24 de octubre de 1925, F7 13208, AN.

145 Nota del 19 de febrero de $1926, F^{7} 1287$, AN.

146 Nota de mayo de $1925, \mathrm{~F}^{7} 13232$, AN.

147 "Ligue d'Action Française. Aix-en-Provence", L'Action française, 22 de mayo de 1908, p. 2.

148 Se hacía notar que la liga se había fundado "sobre todo en vistes a las próximas elecciones legislativas". Informe del comisario de policía M. Soullière, "Au sujet de la ligue d'Action française", 3 de febrero de 1905, BA/1341, en Archives de la Préfecture de Police. 
movimiento y no molestarlo"149. Taittinger también declararía que "la papeleta de voto es un arma imperfecta, pero es un arma" y que "no tenemos el derecho a negligirla" 150 . Pese a criticar a sus antiguos compañeros, el dirigente del Faisceau también tomó sus decisiones tácticas en función de la correlación de fuerzas entre medios de ejecución. "El pueblo francés, en su mayoría, es actualmente de sentimiento antiparlamentario, pero no lo es de espíritu" porque "la gran mayoría de franceses no saben aun lo que reemplazará al parlamento". Se tenía que trabajar, ir hacia la única solución, la toma del poder, no importaba el camino: "la única pregunta que se impone es saber cómo morirá, de muerte dulce, legal y constitucional o de muerte violenta, ilegal y revolucionaria"151.

La praxis de los nacionalistas integrales y de los fascistas puede llevar a pensar que la contrarrevolución francesa fue moderada o, incluso, pusilánime, si se consideran eventos coetáneos como el golpe de mano de septiembre de 1910 en el Fiume por parte de Gabriele d'Annunzio o las insurrecciones de Wolfgang Kapp en marzo de 1920 o la de Adolf Hitler en noviembre de 1923. No obstante, un análisis comparativo más minucioso de las experiencias contrarrevolucionarias saca a relucir que el éxito de las dinámicas subversivas dependian buenamente de ganar dentro del sistema. La concesión del rey Víctor Manuel III a Mussolini en $1922^{152}$ o la nominación de canciller de Hindenburg a Hitler en enero de $1933^{153}$ avalan fehacientemente la hipótesis. Incluso el caso español, paradigmático por instaurarse en el poder a través de la violencia ${ }^{154}$, pone de soslayo que Valois no iba desencaminado cuando señalaba que el golpe de estado moderno tenía que estar cimentado en las masas: "en Alemania, Kapp hizo, con los cuerpos del Baltikum, un golpe militar brillantemente triunfal. Y cuarenta-ocho horas más tarde, tuvo que dejar Berlín frente a la huelga general"155. Por esta razón, no cesaba de repetir "que el Faisceau moviliza combatientes y productores" para "evitar el crimen contra la nación"156.

En definitiva, por extraño que pueda parecer, el caso de la contrarrevolución en Francia ejemplifica que el asalto al poder podia plantearse por cauces electorales, incluso cuando se mantenía una retórica agresiva y se hacia uso de la fuerza callejera. El ethos contrarrevolucionario se caracteriza por hablar sin tapujos de métodos ilegales, por amenazar abiertamente con una insurrección, por invocar la destrucción de la modernidad por todos los medios. Precisamente, es en la divisa de "por todos los medios" donde el espíritu insurgente de los contrarrevolucionarios encuentra toda su coherencia. El éxito de esta cultura

149 Charles Maurras, "La crise", L'Action française, 2 de febrero de 1909, p. 1.

150 Pierre Taittinger, Les Cahiers... op. cit., p. 83.

151 Georges Valois, "La Révolution nationale. La confiance illusoire", Le Nouveau Siècle, 29 de julio de 1926, p. 1.

152 Giulia Albanese, La marcia su Roma, Laterza, Roma, 2008.

153 Richard Bessel, "The Nazi capture of power", Journal of Contemporary History, vol. 39, n 2 , 169-188; Ian Kershaw, Hitler, 1889-1936: Hubris, Norton and Co., Londres, 1999, pp. 487-527.

154 Ferran Gallego, El evangelio fascista. La formación de la cultura politica del franquismo (19301950), Crítica, Barcelona, 2014, pp. 405-431.

155 Georges Valois, L'Homme contre... op. cit., p. 83.

156 Georges Valois, "La Révolution nationale. Le Parlement contre l'épargne et le salaire ouvrier", Le Nouveau Siècle, 31 de julio de 1926, p. 1. 
política radicó en saber compaginar los anhelos subversivos con praxis legales. Valois lo expresó con contundencia a finales de 1926: "si el derrumbe financiero se produce antes de esta fecha, no esperaremos a las elecciones para aportar nuestros remedios, al margen de las leyes o dentro de la más perfecta de las legalidades"157. La adaptabilidad no implicaba, en ningún caso, y esto es lo primordial, el abandono del objetivo último de hacer limpieza con el sistema existente. Los realistas tenían claro que "sólo hay una forma de desembarazarse de la República: el golpe de fuerza"158. Las vias parlamentarias o legalistas no mitigaban ni paliaban el impulso subversivo. Si "se tienen los medios para asegurar la transformación necesaria con el mínimo de trasiego", aseveraba Valois, "se podría hacer también el acomodo legal de la Revolución"159.

El examen de la posición subversiva de la contrarrevolución a través de las vivencias de Georges Valois permite comprender mejor la actitud de las fuerzas contrarrevolucionarias el 6 de febrero de 1934. En 1936, el coronel La Rocque, líder del movimiento de masas Croix de Feu, justificó su decisión de no dar un golpe de fuerza ilegal con los siguientes argumentos: "Despreciar el sufragio universal, arremeter únicamente a golpe de fuerza romántico para ampararse del poder, es una concepción que, en un país occidental, no resista a un examen. Ni Mussolini ni Hitler, a pesar de la ultranza de su doctrina, no cayeron en este error" 160 . Tanto su argumentario como su decisión se inserian perfectamente en la tradición contrarrevolucionaria, cuya cosmovisión queda perfectamente ilustrada en la respuesta de Maurras a las acusaciones de inacción de Valois:

La Action française no ha dejado de ser nunca antiparlamentaria y nadie salvo Valois lo ignora. Siempre ha considerado como una quimera la esperanza de salvar el país por las buenas elecciones, tanto como querer salvar el país por la buena Revolución popular. Fiel a su principio de "por todos los medios, incluso legales", ella ha querido utilizar la tribuna del Parlamento para hacerse oír en el país y tener un medio de acción más sobre los acontecimientos. El fascismo italiano no se ha privado de este tipo de esfuerzo. Ni Déroulède ni Boulanger. ¡No es a París que se puede hacer olvidar el magnífico rol antiparlamentario de Léon Daudet al Parlamento de 1919 !161.

Enviado el (Submission Date): 28/10/2020

Aceptado el (Acceptance Date): 14/12/2020

157 Georges Valois, "Sur la route de Meaux. Réponse à notre voisin”, Le Nouveau Siècle, 28 de novembre de 1926, p. 1.

158 Léon Daudet, "Remerciements", L’Action française, 6 de enero de 1909, p. 1.

159 Georges Valois, “Bilan et prévisions”, Le Nouveau Siècle, 11 de agosto de 1926, p. 1.

160 Informe del 2 de enero de 1926, "Les Croix-de-Feu devant le problème des elections", 451 AP 129, en AN.

161 Charles Maurras, "La Politique. III. Une exécution", L’Action Française, 15 de diciembre de 1925, p. 1. 